\title{
Brain Network Disruption in Whiplash
}

\author{
(D).P. Higgins, (D).M. Elliott, and (D)T.B. Parrish
}

\section{ABSTRACT}

BACKGROUND AND PURPOSE: Whiplash-associated disorders frequently develop following motor vehicle collisions and often involve a range of cognitive and affective symptoms, though the neural correlates of the disorder are largely unknown. In this study, a sample of participants with chronic whiplash injuries were scanned by using resting-state fMRI to assess brain network changes associated with long-term outcome metrics.

MATERIALS AND METHODS: Resting-state fMRI was collected for 23 participants and used to calculate network modularity, a quantitative measure of the functional segregation of brain region communities. This was analyzed for associations with whiplash-associated disorder outcome metrics, including scales of neck disability, traumatic distress, depression, and pain. In addition to these clinical scales, cervical muscle fat infiltration was quantified by using Dixon fat-water imaging, which has shown promise as a biomarker for assessing disorder severity and predicting recovery in chronic whiplash.

RESULTS: An association was found between brain network structure and muscle fat infiltration, wherein lower network modularity was associated with larger amounts of cervical muscle fat infiltration after controlling for age, sex, body mass index, and scan motion ( $t=-4.02$, partial $\left.R^{2}=0.49, P<.001\right)$.

CONCLUSIONS: This work contributes to the existing whiplash literature by examining a sample of participants with whiplash-associated disorder by using resting-state fMRI. Less modular brain networks were found to be associated with greater amounts of cervical muscle fat infiltration suggesting a connection between disorder severity and neurologic changes, and a potential role for neuroimaging in understanding the pathophysiology of chronic whiplash-associated disorders.

ABBREVIATIONS: $r$-fMRI = resting-state fMRI; MFI = muscle fat infiltration; WAD = whiplash-associated disorder(s); MVC = motor vehicle collision

$\mathbf{T}$ he term "whiplash" refers to the transfer of force to the cervical spine via rapid acceleration-deceleration of the head. It is often associated with a motor vehicle collision

Received November 25, 2019; accepted after revision April 14, 2020.

From the Departments of Radiology (J.P.H., T.B.P.) and Physical Therapy and Human Movement Sciences (J.M.E.), Feinberg School of Medicine, Northwestern University, Chicago, Illinois; Discipline of Physiotherapy, Faculty of Health Sciences (J.M.E.), The University of Sydney and the Northern Sydney Local Health District; and The Kolling Research Institute, St. Leonards, NSW, Australia.

The project described originated at Northwestern University, Feinberg School of Medicine, Department of Physical Therapy and Human Movement Sciences, and was supported by the National Institutes of Health (NIH) through Grant Number R01HD079076: Eunice Kennedy Shriver National Institute of Child Health \& Human Development; National Center for Medical Rehabilitation Research

(J.M.E., T.B.P.). The content is solely the responsibility of the authors and does not necessarily represent the official views of the $\mathrm{NIH}$.

Please address correspondence to Todd B. Parrish, PhD, Department of Radiology, Feinberg School of Medicine, Northwestern University, 737 N Michigan Ave, Suite 1600, Chicago, IL 60611; email: toddp@northwestern.edu; @ElliottJSyd

- Indicates open access to non-subscribers at www.ajnr.org

Indicates article with supplemental on-line photos.

http://dx.doi.org/10.3174/ajnr.A6569
(MVC) whereby some patients (about 20\%) develop a complex array of persistent physiologic and psychological sequelae, collectively known as whiplash-associated disorders (WAD). ${ }^{1}$ In addition to neck pain, headache, limited neck range of motion, and bodily pain, patients with persistent WAD may exhibit decreased performance on neuropsychological tests involving attention and working memory. ${ }^{2,3}$

There remains little available literature toward identifying a single salient structural lesion to help explain the disparate signs and symptoms in WAD. ${ }^{4-6}$ Recent work, however, has reported that qualitative and quantitative measures of muscle fat infiltration (MFI) in the cervical spine can be useful for differentiating patients with severe WAD, mild WAD symptoms, idiopathic neck pain, those that have "recovered," and healthy controls. ${ }^{7-11}$ In addition, it has shown early promise as a prognostic marker for recovery trajectories. ${ }^{12}$ The mechanisms underlying the development of MFI remain elusive, but could include disuse, denervation, altered activation of the sympathetic nervous system, stress system dysregulation, and neuroinflammation. ${ }^{13,14}$ 


\begin{tabular}{|c|c|c|c|c|c|c|}
\hline \multirow[b]{2}{*}{ Group/Measure } & \multicolumn{2}{|c|}{ Recovered } & \multicolumn{2}{|c|}{ Moderate } & \multicolumn{2}{|c|}{ Severe } \\
\hline & $\begin{array}{l}\text { Current Study } \\
\qquad(n=5)\end{array}$ & $\begin{array}{l}\text { Entire Study } \\
\qquad(n=30)\end{array}$ & $\begin{array}{l}\text { Current Study } \\
\qquad(n=10)\end{array}$ & $\begin{array}{l}\text { Entire Study } \\
\qquad(n=33)\end{array}$ & $\begin{array}{l}\text { Current Study } \\
\qquad(n=8)\end{array}$ & $\begin{array}{l}\text { Entire Study } \\
\qquad(n=15)\end{array}$ \\
\hline $\operatorname{Sex}(M / F)$ & $3 / 2$ & $13 / 17$ & $8 / 2$ & $4 / 29$ & $6 / 2$ & $3 / 12$ \\
\hline $\mathrm{BMI}$ & $23.5(3.8)$ & $24.9(3.9)$ & $24.5(5.6)$ & $24.4(4.4)$ & $25.3(3.8)$ & $27.6(5.6)$ \\
\hline Age & $35.3(12.8)$ & 33.1 (10.2) & $35.7(13.8)$ & $35.3(12.1)$ & $36.1(13.2)$ & $36.8(11.3)$ \\
\hline Days since MVC & $349.6(149.3)$ & $383.3(35.7)$ & $273(137.3)$ & $385.9(20.4)$ & $385(141.3)$ & $420.3(79.7)$ \\
\hline $\mathrm{NDI}^{\mathrm{b}}$ & $4.8(4.6)$ & $5.5(6.4)$ & $17(9.7)$ & 18.9 (10.2) & 38.5 (13.1) & 30.9 (13.9) \\
\hline $\mathrm{MFI}$ & $18.6(5.5)$ & $17.1(4.9)$ & $21.6(6.6)$ & $20.8(6.9)$ & $21.9(7.2)$ & $23.3(6.8)$ \\
\hline TIDS Total ${ }^{b}$ & $3.4(4.9)$ & $3.0(4.2)$ & $6.3(5.3)$ & $8.4(5.1)$ & $15.1(8.3)$ & $11.0(6.3)$ \\
\hline $\begin{array}{l}\text { PDS Arousal Symptom } \\
\text { Severity }\end{array}$ & $0.4(0.9)$ & $0.8(1.5)$ & $3.1(2.7)$ & $3.9(2.8)$ & $8(3.6)$ & $5.3(4.2)$ \\
\hline Pain ${ }^{b}$ & $1.2(2.2)$ & $1.2(1.6)$ & $3.1(2.7)$ & $3.8(2.6)$ & $6(1.8)$ & $5.1(2.7)$ \\
\hline HADS Depression ${ }^{b}$ & $0.8(1.3)$ & $1.6(2.6)$ & $2.6(2.4)$ & $2.7(2.2)$ & $8.2(4.9)$ & $5.8(4.5)$ \\
\hline Modularity ${ }^{\mathrm{b}}$ & $0.55(0.04)$ & $\mathrm{n} / \mathrm{a}$ & $0.47(0.07)$ & $\mathrm{n} / \mathrm{a}$ & $0.46(0.10)$ & $\mathrm{n} / \mathrm{a}$ \\
\hline
\end{tabular}

Note:-BMI indicates body mass index; NDI, Neck Disability Index; MFI, muscle fat infiltration; TIDS, Traumatic Injury Distress Scale; PDS, Posttraumatic Diagnostic Scale; HADS, Hospital Anxiety and Depression Scale.

${ }^{\text {a }}$ Presented as counts or mean (SD).

${ }^{\mathrm{b}}$ Significant pair-wise comparisons of groups within this study. NDI: Recovered versus moderate $(P=.005)$, recovered versus severe $(P<.001)$, moderate versus severe $(P=.002)$; TIDS: Recovered versus severe $(P=.01)$, moderate versus severe $(P=.02)$; PDS: Moderate versus severe $(P=.007)$, recovered versus severe $(P<.001)$, recovered versus moderate $(P=.01)$; pain: Recovered versus severe $(P=.003)$, moderate versus severe $(P=.02)$; HADS depression: Recovered versus severe $(P=.003)$, moderate versus severe $(P=.01)$; modularity: Recovered versus moderate $(P=.02)$, recovered versus severe $(P=.05)$.

Neuroimaging findings in WAD have been mixed, with some studies reporting changes in cerebral perfusion ${ }^{15,16}$ and white matter tract integrity, ${ }^{17}$ and others failing to find associations by using functional or morphologic imaging. ${ }^{18,19}$ Resting-state-fMRI (rs-fMRI) is a rapidly growing tool and has been widely applied to the investigation of abnormal brain activity in clinical populations. While several studies have revealed connections between rsfMRI and mild-to-severe traumatic brain injury, ${ }^{20,21}$ none thus far have identified similar associations within the WAD population.

Analysis of large-scale networks by using graph theoretical approaches has recently gained traction as a method for the characterization of brain networks observed by using rsfMRI. Within a graph theoretical framework, brain regions can be considered nodes that are linked by edges defined by the strength of pair-wise correlations between pairs of nodes. This topologic arrangement of nodes and edges can be described as a graph, which may be divided into interconnected subnetworks referred to as modules. Modularity has been found to arise in many complex systems, ${ }^{22}$ and advances in neuroimaging have led to the characterization of brain networks as being hierarchically organized and modular systems. ${ }^{23,24}$ Modularity as a quantitative measure can be considered as the ratio between the number of connections (edges), which are located within modules, to the number of connections occurring between modules.

In this preliminary study, we investigated potential links between network modularity and symptom metrics in a sample of 23 patients with chronic WAD. Modularity was chosen because it provides a metric of whole-brain network organization that has shown promise as a marker of brain plasticity and has been applied in the study of a range of clinical conditions, some of which may be superficially similar to WAD, such as mild traumatic brain injury and PTSD. ${ }^{25-30}$ Along with standard clinical scales for assessment of WAD, such as the Neck Disability Index $^{31}$ and the Traumatic Injury Distress Scale, ${ }^{32}$ measures of MFI were included as an outcome metric.

\section{MATERIALS AND METHODS Participants}

This is a secondary ancillary study of participants drawn from a prospective study investigating the neuromuscular mechanisms underlying poor recovery following a whiplash injury (ClinicalTrials.gov Identifier: NCT02157038). In the main study, 97 participants were recruited (19 lost to attrition), consented, and enrolled via an urban academic emergency medicine department and were eligible provided they both reported MVC-related neck pain and were within the Quebec Task Force Classification category of WAD grade II (movement restriction with no radicular symptoms). ${ }^{1}$ Participants were eligible provided they consented and enrolled in the parent study and agreed to undergo imaging of the brain.

Volunteers were not considered if they had a spinal fracture (from the current MVC), radiologic evidence of a spinal cord lesion, or implants contraindicated for MR safety. Participants were not considered if they were pregnant or if, in the absence of an effective form of contraception, they could possibly have conceived since the first day of their last menstrual period.

The study was approved by the relevant Institutional Review Board. The 23 participants (17 female, average age of $35.8 \pm$ 12.8 years) participated in the additional data collection during their regular study visit. Participants were recruited for imaging at least 3 months following their motor vehicle collision (mean $328 \pm 133.16$ days), and were categorized as recovered (5), moderate (10), or severe (8) in symptoms at the time of imaging. Participant characteristics are summarized in the Table.

\section{MR Imaging Data}

MR imaging data were collected by using a $3 \mathrm{~T}$ Prisma (Siemens) scanner with a 64-channel head-neck coil. Structural images were collected by using a 3D T1-weighted scan $(\mathrm{TR}=2.17$ seconds, $\mathrm{TE}=1.69 \mathrm{~ms}, \mathrm{FOV}=256 \times 224,1 \mathrm{~mm}$ isotropic voxel size) of the brain, and a T2-weighted sagittal turbo spin-echo sequence of the cervical spine. A 3D multi-echo 
gradient-echo scan $\quad(F O V=190 \times 320 \mathrm{~mm}, \quad 0.7 \times 0.7 \times 3 \mathrm{~mm}$ voxel size) was collected for the quantification of MFI by acquiring images at echo times where water and fat are in phase and out of phase $\left(\mathrm{TR} / \mathrm{TE}_{1} / \mathrm{TE}_{2}=6.59 / 2.45 / 3.68 \mathrm{~ms}\right)$ to produce water-fat ratio images. rs-fMRI was acquired with a whole-brain multiband $\mathrm{T} 2^{*}$-weighted sequence $(\mathrm{TR}=613 \mathrm{~ms}, \mathrm{TE}=22 \mathrm{~ms}, 2 \mathrm{~mm}$ voxel size, multiband factor $=8$, and 800 volumes).

\section{Preprocessing}

Muscle Fat Infiltration. MFI scores were calculated by using the Dixon water-fat scan as previously described. ${ }^{12}$ Briefly, fat and water compartments of the bilateral multifidi and semispinalis muscles from C3-C7 were manually segmented by a rater blinded to the status of the participant. The mean voxel intensity within each compartment was extracted and MFI was then calculated to generate a percentage of neck muscle fat present for each subject by using the following equation:

$$
\operatorname{MFI}(\%)=\frac{\text { Fat }}{(\text { Fat }+ \text { Water })} * 100
$$

Brain Imaging. Quality control metrics were extracted for T1 and BOLD images by using MRIQC (https://mriqc.readthedocs.io/ en/stable/index.html). ${ }^{33}$ Preprocessing was accomplished by using the Nipype (https://nipype.readthedocs.io/en/latest/) ${ }^{34}$ based tool fMRIPrep version 1.3.2 (https://fmriprep.readthedocs. io/en/stable/) ${ }^{35}$ and AFNI version 19.2.04 (http://afni.nimh.nih. gov/afni). ${ }^{36}$

T1 images were bias-corrected by using ANTs (http://stnava. github.io/ANTs/) N4BiasFieldCorrection, ${ }^{37}$ and skull stripped by using ANTs ants-BrainExtraction. Brain tissue compartments (white matter/gray matter/cerebrospinal fluid) were segmented by using FMRIB Automated Segmentation Tool (FAST; http:// fsl.fmrib.ox.ac.uk/fsl/fslwiki/fast) in native space. ${ }^{38}$ Finally, brain-extracted T1 images were transformed to the Montreal Neurological Institute 152 Nonlinear Asymmetric template version 2009c by using ANTs AntsRegistration tool. ${ }^{39}$

Functional data were section-timing corrected by using AFNI 3dTshift and motion corrected by using FMRIB Intramodal Motion Correction tool (MCFLIRT; http://fsl.fmrib.ox.ac.uk/fsl/ fslwiki/MCFLIRT) before co-registration to the $\mathrm{T} 1$ by using FMRIB Linear Image Registration Tool (FLIRT; https://fsl.fmrib. ox.ac.uk/fsl/fslwiki/FLIRT). ${ }^{40}$ The resulting transforms were concatenated with the T1-to-Montreal Neurological Institute warp and applied in 1 step by using antsApplyTransforms. Framewise displacement was used to exclude high-motion (framewise displacement $>0.5$ ) frames of the time-series, along with 1 subsequent volume. This procedure resulted in an exclusion of between $0.5 \%-25.8 \%$ of data, with a minimum residual time-series of 6.5 minutes (mean $9.09 \pm 1.5 \mathrm{~min}$ ). To remove physiologic noise, 6 principal components of white matter/CSF signals were extracted to create aCompCor (https://nipype.readthedocs.io/en/0.13.1/ interfaces/generated/nipype.algorithms.confounds.html) nuisance regressors. ${ }^{41}$ Motion estimates along with aCompcor regressors and low frequency cosine basis regressors were removed via linear regression; regression, censoring, and smoothing $(6 \mathrm{~mm}$ full width at half maximum) were performed by using AFNI 3dTproject.

\section{Network Modularity Calculation}

Regions of interest were defined as $5 \mathrm{~mm}$-spheres by using the Power 264 coordinates. ${ }^{42}$ Temporal signal-to-noise ratios were calculated for each node/participant, and the average and standard deviation were calculated across all regions $(34.0 \pm 10.1)$. ROIs were excluded if they were more than 2 SD below the mean in any participant (30 regions). Mean time course signals within the remaining ROIs were used to create a $234 \times 234$ Pearson correlation matrix for each participant, which were converted to $z$ scores. Thresholds were used to minimize the number of node pairs considered to constitute edges to a percentage of the strongest connections. To reduce the dependence of results on specific threshold selection, the connection densities used ranged from the top 2\%$10 \%$ in increments of $1 \%$, and an average across this range was taken for use in subsequent analysis, though results across specific thresholds showed similar effects (On-line Figures). This range was chosen because it was used in the construction of the Power 264 region atlas and has been utilized in previous work. ${ }^{42,43}$

The resulting undirected weighted correlation matrices were input to the Brain Connectivity Toolbox (version 2019-03-03) ${ }^{44}$ in Matlab 2016b (MathWorks) to estimate the optimal community structure and calculate modularity. The network was divided into communities by using the Newman spectral algorithm, with the goal of maximizing within-community connections while minimizing connections between communities. ${ }^{45-47}$ Modularity (Q) is then calculated to quantify the extent to which the network is amenable to such subdivision, with higher values of $\mathrm{Q}$ representing networks with a relatively high proportion of withincommunity connections to connections between communities. This form of weighted modularity was calculated as:

$$
Q^{w}=\frac{1}{l^{w}} \sum_{i, j \in N}\left[w_{i, j}-\frac{k_{i}^{w} k_{j}^{w}}{l^{w}}\right] \delta_{m_{i}, m_{j}}
$$

where $i$ and $j$ are connections between nodes, $l^{w}$ is the sum of all weights in the graph, $k_{i}$ is the weighted degree of a node, $m_{i}$ is the module containing node $i$, and $\delta_{m_{i} m_{j}=1}$ if $m_{i}=m_{j}$, and 0 otherwise.

\section{Statistical Analysis}

Potential associations were investigated with multiple linear regression by using $\mathrm{R}$ version 3.4 .4 (http://www.r-project.org/) function $\mathrm{lm}$ in package stats v3.6.1. ${ }^{48}$ Covariates in all models included age, body mass index, sex (coded as 0/1 for male/female), and mean framewise-displacement (fMRI time-series motion). Clinical metrics included Neck Disability Index, ${ }^{31,49}$ MFI, CES-D Depression Scale, ${ }^{50}$ Traumatic Injuries Distress Scale total, Posttraumatic Diagnostic Scale hyperarousal symptom severity, ${ }^{51}$ numeric pain rating scale (0-10), and the Hospital Anxiety and Depression Scale Depression. ${ }^{52}$ Associations were considered significant if they passed Bonferroni correction $(P .05 / 7 ; P \leq .007)$.

\section{RESULTS}

Initial tests for assumptions of linear modeling did not find evidence of collinearity among predictors or extreme non-normality in clinical variables. Among models including only the covariates, the only significant effect observed was of age on MFI, with 
greater age being associated with larger amounts of fat infiltration $(t=3.17, P=.005)$. In the full models, network modularity was found to be negatively associated with MFI $(t=-4.02$, partial $R^{2}=0.49, P<.001$; Fig 1 ) and was not found to be associated with any other clinical metrics. Figure 2 shows the network

\section{MFI Association with Modularity}

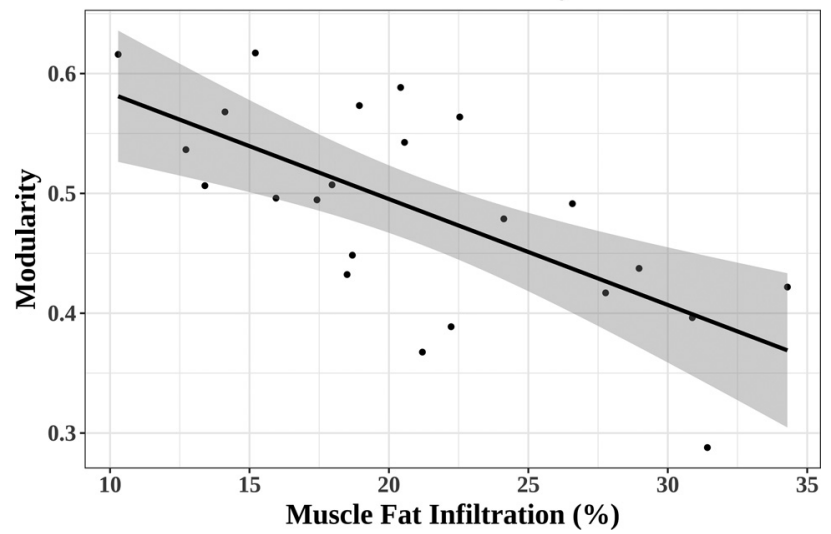

FIG 1. Plot of average modularity (Q) versus MFI (\%) in the cervical spine. Range represents $95 \%$ confidence interval via $\mathrm{R}$ function im (ggplot2). structure for the participants with the highest and lowest MFI scores. No correlation was found between mean scan motion (framewise displacement) and modularity across participants (Pearson $r=-0.21, P=.34$ ).

\section{DISCUSSION}

This study is an investigation of whether rs-fMRI network measures can characterize the clinical status of a heterogeneous group of patients with persistent WAD. While previous research in WAD has yet to accurately and consistently identify markers of structural cervical spine pathology with conventional imaging, this study has found promising results of altered network structure in the brain by using more advanced imaging techniques. Such techniques have potential to influence our mechanistic understanding of WAD and other common yet enigmatic neuromusculoskeletal conditions, such as low back pain, fibromyalgia, osteoarthritis, and rotator cuff pathology.

The rationale for modularity as a chosen measure is 2-fold. First, modularity is a global metric capable of assessing wholebrain network organization without the need for defining a priori regions. This makes it an appropriate target for initial investigation given the lack of existing research into the neural correlates of WAD, as well as the modest sample size of the current ancillary study. In addition, modularity has been implicated in several

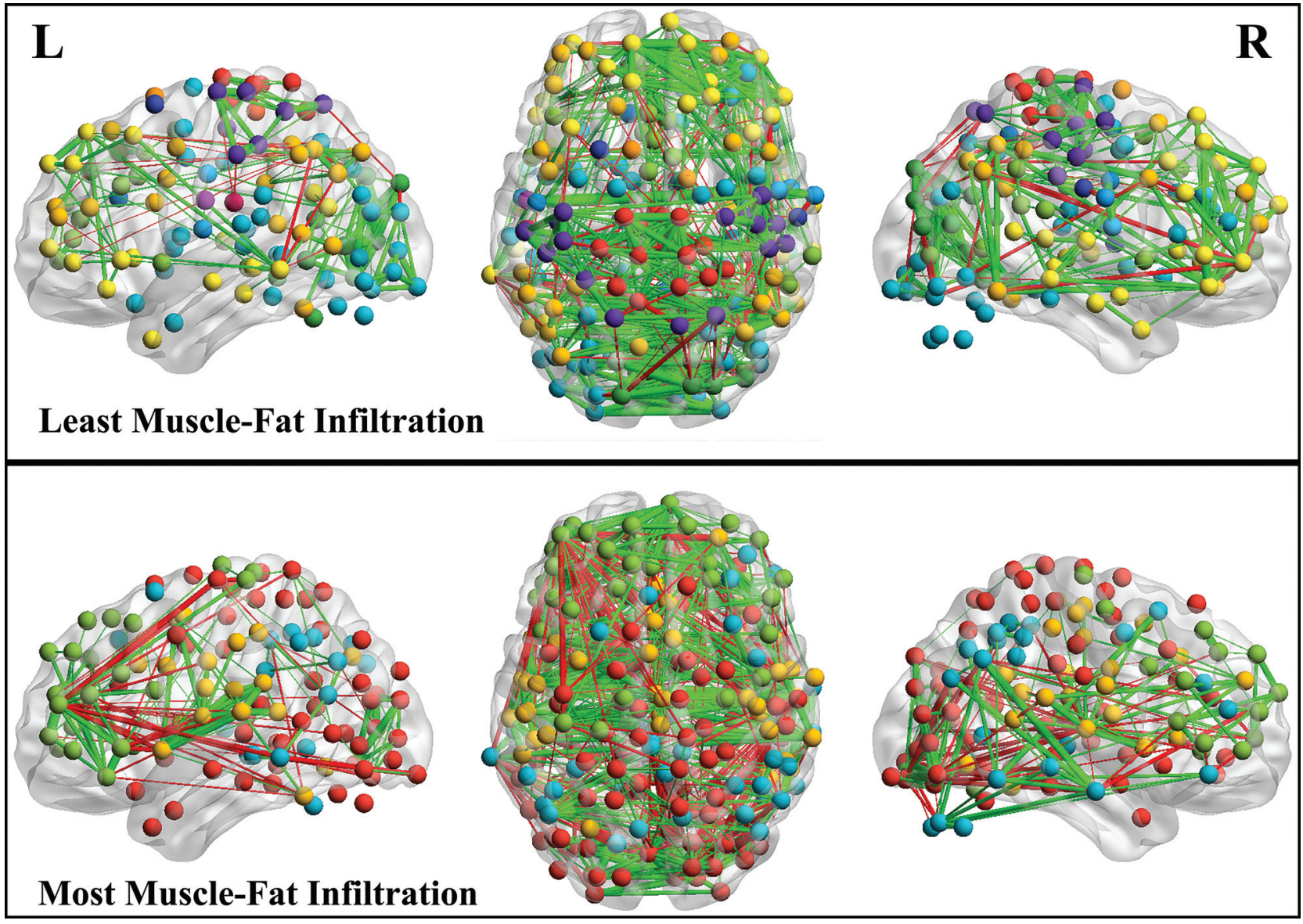

FIG 2. Network structure in the patients with lowest and highest MFI scores. Node colors show communities, green lines show edges within communities, red lines show edges between. The top row exhibits a high level of modularity (high within community connectivity), while the bottom row demonstrates a low level of modularity (fewer communities and more between community connections). 
neurologic conditions that share similarities with the clinical course of WAD, primarily posttraumatic stress disorder ${ }^{29}$ and traumatic brain injury. ${ }^{53,54}$

The prospect of anticipating the directionality of associations with modularity is not straightforward. While work in aging has suggested lower modularity may be detrimental, ${ }^{55}$ research in psychiatric illnesses has reported deleterious effects of modularity bidirectionally, and researchers in traumatic brain injury have reported increases in the acute phase, ${ }^{53}$ yet, the opposite in patients with persistent postconcussive syndrome. ${ }^{54}$ While some work has suggested a possible role of mild traumatic brain injury following whiplash both from kinematic modeling ${ }^{56}$ and observations of symptom similarities, ${ }^{3}$ the prevalence of brain injury in WAD remains largely unknown.

Given the complexities of psychosocial, traumatic, and physical components of WAD, further research is needed to determine how this finding causally relates to the condition. While there is reason to believe network changes may be related to concussive forces, it is also possible that such changes are concurrent with alterations in mood associated with trauma, ${ }^{29,57}$ connected to symptoms of chronic pain, ${ }^{58}$ or related to changes in a neuroimmune network, ${ }^{13}$ in which case, the finding of disrupted modularity may not be specific to WAD but present in posttraumatic stress disorder and traumatic brain injury, for example.

The possibility of altered brain network structure in WAD raises interesting considerations for future research and clinical practice. While most patients who experience an initial whiplash injury go on to make a full recovery, many continue to exhibit symptoms for years following the event, and few quantitative tools are available for differentiating these groups in the acute stage. ${ }^{59,60}$ However, previous work has suggested cervical spine measures of MFI $>20.5 \%$ (range for those with slow recovery was $6.2-40.6 \%$ and rapid recovery was $7.2-22.9 \%$ ) within the first 2 weeks following the MVC resulted in a sensitivity of $87.5 \%$ (true-positive rate) and a specificity of $92.9 \%$ (true-negative rate) for predicting outcomes at 3 months post MVC. ${ }^{12}$ The use of brain network modularity in WAD has the potential to capture a wide range of diverse network connectivity variations in a global metric that may increase prediction when used in conjunction with estimates of MFI and other clinical risk factors.

In addition to the potential diagnostic value, modularity has been shown to be predictive of treatment outcomes in contexts with potential relevance to WAD. High modularity scores have been shown to be associated with greater treatment success by using cognitive training for traumatic brain injury. ${ }^{61}$ In a similar fashion, high baseline modularity has been used to predict larger cognitive gains in response to an exercise intervention in healthy older adults. ${ }^{62}$ In light of these findings and with an ongoing trial investigating the effects of exercise on WAD (which includes fMRI), ${ }^{63}$ network modularity presents a promising marker for treatment prediction.

This study has several limitations. As a global network measure, modularity does not carry explicit information about which sub-networks are disrupted and in what ways. This finding represents a first attempt at applying graph theoretical analysis to a sample of participants with WAD and suggests the need for additional investigation into the types of network reorganization underlying the observed change in modularity. Because no neuropsychological testing was performed, we were unable to investigate these differences in relation to cognitive outcomes such as working memory, executive function, attention, etc.

Furthermore, the intention of this work is not to suggest "we need more imaging" in clinical practice. In purest terms, judicious and informed use of advanced neuroimaging in tandem with other known risk factors may increase confidence of the primary driver of a patient's recovery trajectory, which should ultimately inform a plan of care. ${ }^{64,65}$ The work offers new directions for research in the field to consider multivariate and multisystem pre- and post-collision factors in establishing prognostic phenotypes, leading to new and more informed clinical trials.

Finally, the lack of an association between modularity and the other clinical measures is surprising and could reflect the ancillary nature of this study in that we were not powered to detect differences related to low resolution self-report measures. However, the full sample reflects the known heterogeneity of the WAD condition and provides a foundation for further mechanistic work investigating the bi-directionality of pathways linking peripheral inflammation with neural circuitries sub-serving pain, emotions, muscle structure and function, and outcomes following whiplash injury.

\section{CONCLUSIONS}

Despite evidence for the presence of cognitive symptoms, little is known about the neurobiological correlates of WAD. The discovered association between global brain network organization and a metric of WAD severity highlights the need for further advanced imaging investigations.

\section{ACKNOWLEDGMENTS}

The authors wish to thank the Emergency Medicine Department at Northwestern Memorial Hospital and Marie Wasielewski Chicago, Illinois, for their assistance in the recruitment of acutely injured participants. We also wish to thank all participants for their involvement.

Disclosures: James Elliott-RELATED: Grant: National Institutes of Health, Comments: R01HD079076*; UNRELATED: Board membership: JOSPT, Comments: Accommodation/travel to professional conference; Consultancy: Kaiser Permanente, Comments: Professional development workshops; Employment: University of Sydney, Comments: Professor. Todd Parrish—RELATED: Grant: $\mathrm{NIH}^{*}$; UNRELATED: Grants/Grants Pending: NIH renewal.* *Money paid to institution.

\section{REFERENCES}

1. Spitzer WO, Skovron ML, Salmi LR, et al. Scientific monograph of the Quebec Task Force on Whiplash-Associated Disorders: redefining "whiplash" and its management. Spine (Phila $\mathrm{Pa}$ 1976) 1995;20(8 Suppl):1S-73S Medline

2. Beeckmans K, Crunelle C, Van Ingelgom S, et al. Persistent cognitive deficits after whiplash injury: a comparative study with mild traumatic brain injury patients and healthy volunteers. Acta Neurol Belg 2017;117:493-500 CrossRef Medline

3. Ettlin TM, Kischka U, Reichmann S, et al. Cerebral symptoms after whiplash injury of the neck: a prospective clinical and neuropsychological study of whiplash injury. J Neurol Neurosurg Psychiatry 1992;55:943-48 CrossRef Medline 
4. Matsumoto M, Ichihara D, Okada E, et al. Cross-sectional area of the posterior extensor muscles of the cervical spine in whiplash injury patients versus healthy volunteers-10 year follow-up MR study. Injury 2012;43:912-16 CrossRef Medline

5. Ronnen HR, de Korte PJ, Brink PR, et al. Acute whiplash injury: is there a role for MR imaging?-a prospective study of 100 patients. Radiology 1996;201:93-96 CrossRef Medline

6. Matsumoto M, Ichihara D, Okada E, et al. Modic changes of the cervical spine in patients with whiplash injury: a prospective 11-year follow-up study. Injury 2013;44:819-24 CrossRef Medline

7. Elliott J, Jull G, Noteboom JT, et al. Fatty infiltration in the cervical extensor muscles in persistent whiplash-associated disorders: a magnetic resonance imaging analysis. Spine (Phila $\mathrm{Pa}$ 1976) 2006;31:E847-55 CrossRef

8. Elliott JM, O'Leary S, Sterling M, et al. G. Magnetic resonance imaging findings of fatty infiltrate in the cervical flexors in chronic whiplash. Spine (Phila Pa 1976) 2010;35:948-54

9. Karlsson A, Leinhard OD, Åslund U, et al. An investigation of fat infiltration of the multifidus muscle in patients with severe neck symptoms associated with chronic whiplash-associated disorder. $J$ Orthop Sports Phys Ther 2016;46:886-93 CrossRef Medline

10. Abbott R, Peolsson A, West J, et al. The qualitative grading of muscle fat infiltration in whiplash using fat and water magnetic resonance imaging. Spine J 2018;18:717-25 CrossRef

11. Elliott J, Sterling M, Noteboom JT, et al. Fatty infiltrate in the cervical extensor muscles is not a feature of chronic, insidious-onset neck pain. Clin Radiology 2008;63:681-87 CrossRef

12. Elliott JM, Courtney DM, Rademaker A, et al. The rapid and progressive degeneration of the cervical multifidus in whiplash: an MRI study of fatty infiltration. Spine (Phila Pa 1976) 2015;40:E694700 CrossRef Medline

13. Nusslock R, Brody GH, Armstrong CC, et al. Higher peripheral inflammatory signaling associated with lower resting-state functional brain connectivity in emotion regulation and central executive networks. Biol Psychiatry 2019;86:153-62 CrossRef Medline

14. Passatore $M$, Roatta $S$. Influence of sympathetic nervous system on sensorimotor function: whiplash associated disorders (WAD) as a model. Eur J Appl Physiol 2006;98:423-49 CrossRef Medline

15. Linnman C, Appel L, Söderlund A, et al. Chronic whiplash symptoms are related to altered regional cerebral blood flow in the resting state. Eur J Pain 2009;13:65-70 CrossRef Medline

16. Vállez García D, Doorduin J, Willemsen AT, et al. Altered regional cerebral blood flow in chronic whiplash associated disorders. EBioMedicine 2016;10:249-57 CrossRef Medline

17. Jang $\mathrm{SH}$, Kwon $\mathrm{YH}$. A review of traumatic axonal injury following whiplash injury as demonstrated by diffusion tensor tractography. Front Neurol 2018;9:57 CrossRef Medline

18. Sturzenegger M, Radanov BP, Winter P, et al. MRI-based brain volumetry in chronic whiplash patients: no evidence for traumatic brain injury. Acta Neurol Scand 2008;117:49-54 CrossRef Medline

19. Radanov BP, Bicik I, Dvorak J, et al. Relation between neuropsychological and neuroimaging findings in patients with late whiplash syndrome. J Neurol Neurosurg Psychiatry 1999;66:485-89 CrossRef Medline

20. Churchill NW, Hutchison MG, Graham SJ, et al. Connectomic markers of symptom severity in sport-related concussion: Wholebrain analysis of resting-state fMRI. Neuroimage Clin 2018;18:51826 CrossRef Medline

21. Konstantinou N, Pettemeridou E, Stamatakis EA, et al. Altered resting functional connectivity is related to cognitive outcome in males with moderate-severe traumatic brain injury. Front Neurol 2019;9:1163 CrossRef Medline

22. Newman MEJ. The structure and function of networks. Computer Physics Communications 2002;147:40-45 CrossRef

23. Sporns O, Betzel RF. Modular brain networks. Annu Rev Psychol 2016;67:613-40 CrossRef Medline

24. Wig GS. Segregated systems of human brain networks. Trends Cogn Sci (Regul Ed) 2017;21:981-96 CrossRef Medline
25. Rudie JD, Brown JA, Beck-Pancer D, et al. Altered functional and structural brain network organization in autism. Neuroimage Clin 2012;2:79-94 CrossRef Medline

26. Gratton C, Nomura EM, Pérez F, et al. Focal brain lesions to critical locations cause widespread disruption of the modular organization of the brain. J Cogn Neurosci 2012;24:1275-85 CrossRef Medline

27. Alexander-Bloch A, Gogtay N, Meunier D, et al. Disrupted modularity and local connectivity of brain functional networks in childhood-onset schizophrenia. Front Syst Neurosci 2010;4:147 CrossRef Medline

28. Ye M, Yang T, Qing P, et al. Changes of functional brain networks in major depressive disorder: a graph theoretical analysis of resting-state fMRI. PloS One 2015;10:e133775-e0133775 CrossRef Medline

29. Akiki TJ, Averill CL, Wrocklage KM, et al. Default mode network abnormalities in posttraumatic stress disorder: A novel networkrestricted topology approach. Neuroimage 2018;176:489-98 CrossRef Medline

30. de Haan W, van der Flier WM, Koene T, et al. Disrupted modular brain dynamics reflect cognitive dysfunction in Alzheimer's disease. Neuroimage 2012;59:3085-93 CrossRef Medline

31. Vernon H, Mior S. The Neck Disability Index: a study of reliability and validity. J Manipulative Physiol Ther 1991;14:409-15 Medline

32. Walton DM, Krebs d, moulden d, et al. The Traumatic Injuries Distress scale: A new tool that quantifies distress and has predictive validity with patient-reported outcomes. J Orthop Sports Phys Ther 2016;46:920-28 CrossRef Medline

33. Esteban O, Birman D, Schaer M, et al. MRIQC: Advancing the automatic prediction of image quality in MRI from unseen sites. PLoS One 2017;12:e0184661 CrossRef Medline

34. Gorgolewski K, Burns CD, Madison C, et al. Nipype: a flexible, lightweight and extensible neuroimaging data processing framework in python. Front Neuroinform 2011;5:13 CrossRef Medline

35. Esteban O, Markiewicz CJ, Blair RW, et al. fMRIPrep: a robust preprocessing pipeline for functional MRI. Nat Methods 2019;16:11116 CrossRef Medline

36. Cox RW. AFNI: software for analysis and visualization of functional magnetic resonance neuroimages. Comput Biomed Res 1996;29:162-73 CrossRef Medline

37. Tustison NJ, Avants BB, Cook PA, et al. N4ITK: improved N3 bias correction. IEEE Trans Med Imaging 2010;29:1310-20 CrossRef Medline

38. Zhang Y, Brady M, Smith S. Segmentation of brain MR images through a hidden Markov random field model and the expectation-maximization algorithm. IEEE Trans Med Imaging 2001;20:4557 CrossRef Medline

39. Fonov V, Evans AC, Botteron K; Brain Development Cooperative Group, et al. Unbiased average age-appropriate atlases for pediatric studies. NeuroImage 2011;54:313-27 CrossRef Medline

40. Jenkinson M, Smith S. A global optimisation method for robust affine registration of brain images. Med Image Anal 2001;5:143-56 CrossRef Medline

41. Behzadi Y, Restom K, Liau J, et al. A component based noise correction method (CompCor) for BOLD and perfusion based fMRI. Neuroimage 2007;37:90-101 CrossRef Medline

42. Power JD, Cohen AL, Nelson SM, et al. Functional network organization of the human brain. Neuron 2011;72:665-78 CrossRef Medline

43. Gallen CL, Baniqued PL, Chapman SB, et al. Modular brain network organization predicts response to cognitive training in older adults. PLoS One 2016;11:e0169015 CrossRef Medline

44. Rubinov M, Sporns O. Complex network measures of brain connectivity: uses and interpretations. Neuroimage 2010;52:1059-69 CrossRef Medline

45. Newman ME. Modularity and community structure in networks. Proc Natl Acad Sci USA 2006;103:8577-82 CrossRef Medline 
46. Reichardt J, Bornholdt S. Statistical mechanics of community detection. Phys Rev E Stat Nonlin Soft Matter Phys 2006;74:016110 Pt 2 CrossRef Medline

47. Newman MEJ. Finding community structure in networks using the eigenvectors of matrices. Physical Review 2006;74:036104 CrossRef

48. $\mathrm{R}$ Core Team. R: A language and environment for statistical computing [computer program]. Vienna, Austria: R Foundation for Statistical Computing 2018 https://www.R-project.org/

49. Vernon H. The Neck Disability Index: state-of-the-art, 1991-2008. J Manipulative Physiol Ther 2008;31:491-502 CrossRef Medline

50. Andresen EM, Malmgren JA, Carter WB, et al. Screening for depression in well older adults: evaluation of a short form of the CES-D. Am J Prev Med 1994;10:77-84 CrossRef

51. McCarthy S. Post-Traumatic Stress Diagnostic Scale (PDS). Occup Med (Lond) 2008;58:379 CrossRef Medline

52. Zigmond AS, Snaith RP. The hospital anxiety and depression scale. Acta Psychiatr Scand 1983;67:361-70 CrossRef Medline

53. Han K, Mac Donald CL, Johnson AM, et al. Disrupted modular organization of resting-state cortical functional connectivity in U.S. military personnel following concussive 'mild' blast-related traumatic brain injury. Neuroimage 2014;84:76-96 CrossRef

54. Messé A, Caplain S, Pélégrini-Issac M, et al. Specific and evolving resting-state network alterations in post-concussion syndrome following mild traumatic brain injury. PLoS One 2013;8:e65470 CrossRef

55. Song J, Birn RM, Boly $\mathrm{M}$, et al. Age-related reorganizational changes in modularity and functional connectivity of human brain networks. Brain Connect 2014;4:662-76 CrossRef Medline

56. Elkin BS, Elliott JM, Siegmund GP. Whiplash injury or concussion? A possible biomechanical explanation for concussion symptoms in some individuals following a rear-end collision. J Orthop Sports Phys Ther 2016;46:874-85 CrossRef Medline

57. Sartin-Tarm A, Cisler J, Ross M. Resting state functional neural network modularity among adult women with PTSD. Biological Psychiatry 2018;83:S137 CrossRef

58. Mano H, Kotecha G, Leibnitz K, et al. Classification and characterisation of brain network changes in chronic back pain: A multicenter study. Wellcome Open Res 2018;3:19 CrossRef Medline

59. Gargan MF, Bannister GC. The rate of recovery following whiplash injury. Eur Spine J 1994;3:162-64 CrossRef Medline

60. Carroll LJ, Hogg-Johnson S, Cote P, et al. Course and prognostic factors for neck pain in workers: results of the Bone and Joint Decade 2000-2010 Task Force on Neck Pain and Its Associated Disorders. Spine (Phila Pa 1976) 2008;33:S93-100 CrossRef Medline

61. Arnemann KL, Chen AJW, Novakovic-Agopian T, et al. Functional brain network modularity predicts response to cognitive training after brain injury. Neurology 2015;84:1568-74 CrossRef Medline

62. Baniqued PL, Gallen CL, Voss MW, et al. Brain network modularity predicts exercise-related executive function gains in older adults. Front Aging Neurosci 2017;9:426 CrossRef Medline

63. Peolsson A, Karlsson A, Ghafouri B, et al. Pathophysiology behind prolonged whiplash associated disorders: study protocol for an experimental study. BMC Musculoskelet Disord 2019;20:51 CrossRef Medline

64. Walton DM, Elliott JM. A new clinical model for facilitating the development of pattern recognition skills in clinical pain assessment. Musculoskelet Sci Pract 2018;36:17-24 CrossRef Medline

65. Walton DM, Elliott JM. An integrated model of chronic whiplashassociated disorder. J Orthop Sports Phys Ther 2017;47:462-71 CrossRef Medline 